\title{
Case Report: Cognitive Impairment without Clinical Spinal Disease May Be the First Sign of HTLV-1 Neurological Alteration
}

\author{
Aline Rejane Rosa de Castro, ${ }^{1,2}$ Ludimila Labanca, ${ }^{1,2}$ Luciana Macedo de Resende, ${ }^{2}$ and Denise Utsch-Gonçalves ${ }^{1,2 *}$ \\ ${ }^{1}$ Infectious Diseases and Tropical Medicine, Universidade Federal de Minas Gerais, Belo Horizonte, Brazil; ${ }^{2}$ Speech Language and Hearing \\ Sciences, Universidade Federal de Minas Gerais, Belo Horizonte, Brazil
}

\begin{abstract}
Human t-cell lymphotropic virus type 1 (HTLV-1)-associated myelopathy (HAM) is a progressive neurological disease whose diagnosis is defined by clinical manifestations and seropositivity for HTLV-1 infection. Cognitive impairment $(\mathrm{Cl})$ is considered to occur after spinal impairment. A 51-year-old HTLV-1-infected man classified as an asymptomatic carrier presented difficulties in listening comprehension and executive memory. He was assessed for central auditory processing (CAP), cognition (event-related auditory evoked potential [P300]), and otoneurological functions (galvanic vestibular-evoked myogenic potential [gVEMP]). Altered responses were found in CAP, P300, and gVEMP, but the neurological examination and cognitive screening were normal. After a 2-year follow-up, we disclosed a positive Babinski sign, a mild Cl, worsened $\mathrm{P} 300$, and gVEMP latencies, and the patient reported progressive lumbar pain and difficulty running. He was, then, reclassified as HAM. The first examination, in 2016, had already shown abnormal results in P300 and gVEMP despite the HTLV-1-asymptomatic carrier status. Therefore, tests that provide subclinical measures of neurological disease progression can be useful tools for an early diagnosis and intervention in HTLV-1 patients. Electrophysiological results had worsened as well as the clinical status and the cognitive function and the progression from asymptomatic status to an HTLV-1-associated neurological disease occurred within 2 years. Thus, HTLV-1-infected individuals with complaints of $\mathrm{Cl}$, hearing, or otoneurological manifestations should be submitted to neuropsychological and electrophysiological tests, allowing them to be properly cared in case of HAM progression.
\end{abstract}

\section{INTRODUCTION}

Human t-cell lymphotropic virus type 1 (HTLV-1)-associated myelopathy (HAM) is a progressive neurological disease. ${ }^{1-3}$ Approximately $4 \%$ of infected individuals will develop HAM. ${ }^{4,5}$ However, subclinical manifestations may precede the diagnosis of HAM and extrapolate its typical medullary symptoms, including otoneurological, ${ }^{6-8}$ subcortical, and cortical ${ }^{9,10}$ impairment.

Human t-cell lymphotropic virus type 1-asymptomatic carriers have shown abnormalities in immunological, ${ }^{11}$ electrophysiological, ${ }^{6,7}$ and imaging ${ }^{9,12,13}$ tests. Neuropsychological tests have shown that both HTLV-1asymptomatic carriers and patients with a HAM diagnosis had an increased degree of cognitive impairment $(\mathrm{Cl}),{ }^{14-16}$ although $\mathrm{Cl}$ is not expected to occur early in the infection. It is believed that $\mathrm{Cl}$ will appear in later stages of disease progression and not as its first symptom. ${ }^{10,14}$ This study presents a case report of auditory and cognitive alterations in an HTLV-1-asymptomatic carrier who was 2 years later diagnosed with HAM.

\section{CASE REPORT}

A 51-year-old Brazilian man was first evaluated with HTLV1 infection in 2016 and has been followed semiannually since then. The seropositivity for HTLV-1 was detected during a blood donation screening assessed by ELISA and confirmed by Western blot analysis (WB HTLV 2.4, Genelabs Diagnostics, Singapore) and by qualitative PCR of DNA extracted from blood cells. Tests for HIV and syphilis were negative. He denied a history of epilepsy, major psychiatric disorders,

*Address correspondence to Denise Utsch-Gonçalves, Faculty of Medicine, Universidade Federal de Minas Gerais, Av. Alfredo Balena, 190, Belo Horizonte 30130-100, Brazil. E-mail: deniseg@medicina. ufmg.br traumatic brain injury, alcoholism, and drug addiction. Thyroid function and B12/folate were normal. Proviral load and cerebrospinal fluid analyses were not available. He had 14 years of formal education. As he reported memory and listening comprehension difficulties that had been interfering in his professional activities for about 1 year, he underwent hearing screening tests, central auditory processing (CAP), and electrophysiological assessments. Other possible causes of $\mathrm{Cl}$ and neurological diseases were excluded by a normal magnetic resonance imaging (MRI) of the brain. He had no other complaints and presented positive personality characteristics.

Audiometric thresholds and word recognition scores were within normal ranges. Middle ear impedance was normal, but the contralateral acoustic reflexes were absent. The CAP assessment consisted of behavioral and electrophysiological measures. Event-related auditory evoked potential (P300) response was obtained from an $\mathrm{Fz}-\mathrm{A} 1-\mathrm{A} 2$ electrode array with 300 alternate tone bursts of $1,000 \mathrm{~Hz}$ and $2,000 \mathrm{~Hz}$ (rare), $0.9 / \mathrm{s}$ rate, $90 \mathrm{dBSPL}, 1$-to- $30 \mathrm{~Hz}$ filter, $20 / 80$ oddball paradigm, and a maximum $5 \mathrm{~K} \Omega$ of electrode impedance. The behavioral auditory tests consisted of Staggered Spondaic Words (SSW), Synthetic Sentence Identification test with Ipsilateral Competing Message, Masking Level Difference, Pitch Pattern Sequence, Gaps-in-Noise (GIN), and Words-in-Noise tests. The tests were performed in a soundproof booth using a twochannel audiometer coupled to a media player and Telephonics $®$ TDH-39 headphones.

Both behavioral and electrophysiological assessments showed abnormal responses. The results on SSW, SSI-MCI, and GIN tests were altered for a normal-hearing adult. The P300 wave was delayed as it was registered at $401.97 \mathrm{~ms}$. As we found a normal peripheral hearing with an unexpected CAP alteration, the patient was subjected to otoneurological assessment and image examinations.

Galvanic vestibular-evoked myogenic potential (gVEMP) ${ }^{17}$ of the inferior limb was performed to test patient's postural 
reflex, and the result was altered, characterized by a latency delay of both short and middle wave peaks. The neurological examination was normal as well as the Osame's Motor Disability Score (OMDS). ${ }^{18}$ The screening for depression indicated normal mood. ${ }^{19}$ The Montreal Cognitive Assessment $(\mathrm{MoCA})^{20}$ indicated normal cognitive skills. The MRI of the brain and the spine was normal. Despite the subclinical alterations found in behavioral CAP tests, P300, and gVEMP, the patient was classified as an HTLV-1-asymptomatic carrier according to the criteria for HAM diagnosis. ${ }^{1}$

Two years later, the patient complained of executive memory worsening. We performed the same test battery formerly conducted. The peripheral hearing remained normal. The behavioral CAP tests showed the same previous alterations. Event-related auditory evoked potential and gVEMP results worsened when compared with those in 2016. The screening for depression was normal. Differently, the MoCA indicated a mild $\mathrm{Cl}$, and the neurological examination disclosed a Babinski sign. When asked about his motor and sensitive skills, the patient reported the onset of difficulty running and progressive lumbar pain. According to the literature, low back pain is a frequent early symptom of HAM manifestation. ${ }^{21,22}$ The OMDS changed to grade 1 (normal gait but runs slowly). The patient was reclassified as HAM based on the clinical criteria and exclusion of other disorders that could resemble HAM. ${ }^{1}$ The initial and final assessment results are shown in Table 1.

\section{DISCUSSION}

Human t-cell lymphotropic virus-associated myelopathy affects mainly the lumbar spine and follows an upward impairment, although the entire neuroaxis can be compromised from the beginning. ${ }^{2,3,23}$ Later on, with the disease progression, the cerebral structures can be affected. ${ }^{9,13}$ Based on the present case, the subcortical and cortical involvement in HTLV-1 infection can precede the spinal cord involvement, which, to date, has been scarcely noticed in the literature. Because HTLV-1 has been considered a neglected disease, and the treatment of HAM is palliative and symptomcentered, ${ }^{5}$ CAP deficits can be improved through auditory training associated with enhanced neuroplasticity and neurocognitive performance, thereby resulting in a better quality of life. ${ }^{24}$

The initial gVEMP responses showed an unexpected subclinical functional spinal damage because the patient had been classified as an HTLV-1-asymptomatic carrier by that time. ${ }^{6,7}$ In the nervous system pattern of damage caused by HTLV-1, a progressive impairment of the motor spine occurs and lumbar pain has been linked to early stages of HAM manifestation. ${ }^{21,22}$ After 2 years, he progressed to neurological alterations compatible with HAM. A wide variation in the progression rates of HAM has been described. ${ }^{25}$ Some infected individuals are classified as rapid progressors, which means evolving from asymptomatic status to advanced HAM in around 2 years. ${ }^{23}$ The pattern of rapid progression has been observed in the present case, although the patient has not reached the advanced HAM stage. Currently, the progressive impairment of the motor spine in HAM precedes the $\mathrm{Cl}$; however, the cognitive tests have not been considered in the neurological evaluation of HTLV-1asymptomatic infection. ${ }^{1,3,5,18}$

Little is known about the CAP in HTLV-1-infected individuals, although $\mathrm{Cl}$ is evident during HAM progression. ${ }^{14-16,26,27}$ Poor performance in tasks of selective attention, auditory memory, and temporal processing pointed to functional deficits in the auditory pathway. Fukushima et al. ${ }^{26}$ used P300 to show the occurrence of $\mathrm{Cl}$ in HAM patients. They found a latency delay of the P300 wave in HAM patients when compared with normal controls. The same P300 alteration was found in the present case with HTLV-1-asymptomatic infection. Therefore, the cortex involvement may occur in parallel or before spinal cord involvement in HTLV-1 infection. ${ }^{15}$ In addition, absent acoustic reflexes corroborate that the central auditory nervous system had been affected. ${ }^{28}$

TABLE 1

Patient's performance on central auditory processing, behavioral and electrophysiological tests, cognitive and motor screenings, and clinical status during the initial and the final assessments: results of a 2-year follow-up

\begin{tabular}{|c|c|c|c|c|}
\hline & & 2016 & 2018 & Reference \\
\hline Spondaic Staggered Word (dichotic & Left & 90 & 90 & $\geq 90$ \\
\hline listening task) (\%) & Right & $50^{\star}$ & $55^{\star}$ & $\geq 90$ \\
\hline Synthetic Sentence Identification & Left & $50^{*}$ & $60^{*}$ & $\geq 70$ \\
\hline (monotic listening task) (\%) & Right & 90 & 90 & $\geq 70$ \\
\hline \multirow[t]{2}{*}{ Words-in-Noise test (\%) } & Left & 100 & 96 & $\geq 70$ \\
\hline & Right & 96 & 92 & $\geq 70$ \\
\hline $\begin{array}{l}\text { Pitch Pattern Sequence (temporal } \\
\text { ordination task) (\%) }\end{array}$ & - & 96,6 & 93,3 & $\geq 90$ \\
\hline $\begin{array}{l}\text { Gaps-in-Noise (temporal resolution task) } \\
\text { (ms) }\end{array}$ & - & $8^{*}$ & $8^{\star}$ & $<8$ \\
\hline $\begin{array}{l}\text { Masking Level Difference (binaural } \\
\text { integration task) }(n)\end{array}$ & - & 10 & 10 & $\geq 10$ \\
\hline $\begin{array}{l}\text { Event-related auditory evoked potential } \\
\text { (ms) }\end{array}$ & - & $401.97^{*}$ & $404.35^{\star}$ & $\leq 380$ \\
\hline \multirow{2}{*}{$\begin{array}{l}\text { Vestibular-evoked myogenic potential } \\
\text { (ms) }\end{array}$} & Short & $79.54^{\star}$ & $80.80^{*}$ & $\leq 64$ \\
\hline & Middle & $135.05^{\star}$ & $138.35^{\star}$ & $\leq 125$ \\
\hline Montreal Cognitive Assessment $(n)$ & - & 26 & $23^{*}$ & $\geq 26$ \\
\hline Osame's motor disability scale $(n)$ & - & 0 (normal) & 1 (abnormal) $)^{\star}$ & - \\
\hline Clinical status & - & Asymptomatic & $\begin{array}{l}\text { Human t-cell lymphotropic } \\
\text { virus-associated myelopathy* }\end{array}$ & - \\
\hline
\end{tabular}

${ }^{*}$ Altered result. 
Causes other than HTLV-1 were considered for the alterations in behavioral tests and P300, but nothing was found. For example, the mood was normal as well as the brain MRI and the patient referred a very good level of schooling. Depression and attention deficits can interfere in P300, but these diagnoses are not plausible for the present case because the patient reported a high performance in daily life and in professional and social activities along with no complaints related to depression. Therefore, these major confounding variables were most likely controlled. Thus, we consider that CAP deficits and $\mathrm{Cl}$ were related to subtle alterations in auditory pathways and subcortical and cortical areas caused by early and subclinical stages of HAM. The borderline score at MoCA in the first evaluation, associated with the altered $\mathrm{P} 300$, was an indication of a $\mathrm{Cl}$ in progress, which was confirmed by the worsening of the patient's MoCA score 2 years later, characterizing a mild $\mathrm{Cl}^{29}$ The normal peripheral hearing was normal, and $\mathrm{P} 300$ and MoCA alterations have pointed to a $\mathrm{Cl}$ that had occurred before the HAM diagnosis.

Along with the electrophysiological alteration, poor performance was observed in selective attention, integration, and temporal processing tasks. These auditory abilities are key in CAP and are directly related to cognitive functioning. ${ }^{30}$ Both behavioral and electrophysiological results can be affected by aging, lower educational level, hearing loss, and mood status. None of these variables were present, and the P300 latency more than $400 \mathrm{~ms}$, which was found, is certainly classified as a delayed latency for a 51-year-old person with normal peripheral hearing and with a high level of formal education. $^{31}$

In the present case report, we have followed the progression from HTLV-1-asymptomatic status to HAM and have showed that the impairment of subcortical and cortical function can be detected early in HTLV-1 neurological disease progression through an electrophysiological assessment. Although presented as a case report, this patient participates in an open cohort of HTLV-1-infected ex-blood donors who have been followed by the HTLV-1/2 Interdisciplinary Research Group (GIPH) since 1997. ${ }^{32}$ We believe that the diagnosis of $\mathrm{Cl}$ has been more frequent and detected earlier by the GIPH when compared with the literature because of the use of electrophysiological measures and screening for cognitive functions in the individuals with an HTLV-1asymptomatic infection. Some of them, later on, have evolved to HAM. ${ }^{4,6-8,33}$ We consider that an HTLV-1-asymptomatic carrier that complains of any cognitive-related manifestations should undergo a battery of neuropsychological and electrophysiological tests to assess subclinical changes regardless of HAM diagnosis.

Received March 19, 2019. Accepted for publication October 20, 2019.

Published online December 12, 2019.

Acknowledgment: The American Society of Tropical Medicine and Hygiene (ASTMH) assisted with publication expenses.

Authors' addresses: Aline Rejane Rosa de Castro, Ludimila Labanca, and Denise Utsch-Gonçalves, Health Sciences, Infectious Diseases and Tropical Medicine, Faculty of Medicine, Universidade Federal de Minas Gerais (UFMG), Brazil, E-mails: acastro.rrc@gmail.com, ludlabanca@gmail.com, and deniseg@medicina.ufmg.br. Luciana Macedo de Resende, Health Sciences-Speech, Language, and Hearing Sciences, Faculty of Medicine, Universidade Federal de Minas Gerais (UFMG), Brazil, E-mail: Imacedo.luciana@gmail.com.

\section{REFERENCES}

1. Castro-costa CMDE et al.,2006. Proposal for diagnostic criteria of tropical spastic paraparesis/HTLV-I- associated myelopathy (HAM/TSP). AIDS Res Hum Retroviruses 22: 931-935.

2. Cervilla J, Cartier L, García L, 2006. Brain and spinal cord magnetic resonance imaging in spastic paraparesis associated to human T-lymphotropic virus [article in Spanish]. Rev Med Chil 134: 1010-1018.

3. Osame M, Usuku K, Izumo S, ljichi N, Amitani H, Igata A, Matsumoto M, Tara M, 1986. HTLV-I associated myelopathy, a new clinical entity. Lancet 1: 1031-1032.

4. Romanelli LC, Caramelli P, Martins ML, Goncalves DU, Proietti FA, Ribas JG, Araujo MG, Carneiro-Proietti AB, 2013. Incidence of human T cell lymphotropic virus type 1-associated myelopathy/ tropical spastic paraparesis in a long-term prospective cohort study of initially asymptomatic individuals in Brazil. AIDS Res Hum Retroviruses 29: 1199-1202.

5. Tanajura D, Castro N, Oliveira P, Neto A, Muniz A, Carvalho NB, Orge G, Santos S, Glesby MJ, Carvalho EM, 2015. Neurological manifestations in human T-cell lymphotropic virus type 1 (HTLV-1)Infected individuals without HTLV-1-associated myelopathy/ tropical spastic paraparesis: a longitudinal cohort study. Clin Infect Dis 61: 49-56.

6. Felipe L, Goncalves DU, Santos MAR, Proietti FA, Ribas JGR, Carneiro-Proietti AB, Lambertucci JR, 2008. Vestibular-evoked myogenic potential (VEMP) to evaluate cervical myelopathy in human T-cell lymphotropic virus type I infection. Spine (Phila Pa 1976) 33: 1180-1184.

7. Felipe L, Kingma $H$, Lambertucci JR, Carneiro-Proietti $A B$, Gonçalves DU, 2013. Testing the vestibular evoked myogenic potential (VEMP) to identify subclinical neurological alterations in different phases of human T-lymphotropic virus type 1 infection. Spine J 13: 397-401.

8. Labanca L, Starling ALB, de Sousa-Pereira SR, Romanelli LCF, de Freitas Carneiro-Proietti AB, Carvalho LN, Fernandes DR, Utsch Gonçalves D, 2015. Electrophysiological analysis shows dizziness as the first symptom in human T cell lymphotropic virus type-associated myelopathy/tropical spastic paraparesis. AIDS Res Hum Retroviruses 31: 649-654.

9. Schütze M, Romanelli LCF, Rosa DV, Carneiro-Proietti ABF, Nicolato R, Romano-Silva MA, Brammer M, de Miranda DM, 2017. Brain metabolism changes in patients infected with HTLV-1. Front Mol Neurosci 10: 52.

10. Champs APS, de Azeredo Passos VM, Carvalho G, Barreto SM, Meirelles C, Caramelli P, 2019. Cognitive impairment in HTLV-1-associated myelopathy, proviral load and inflammatory markers. Int J Infect Dis 84: 121-126.

11. Starling ALB et al., 2015. Immunological signature of the different clinical stages of the HTLV-1 infection: Establishing serum biomarkers for HTLV-1-associated disease morbidity. Biomarkers 20: 502-512.

12. Mattson DH, Mcfarlin DE, Mora C, Zaninovic V, 1987. Centralnervous-system lesions detected by magnetic resonance imaging in an HTLV-1 antibody positive symptomless individual. Lancet 2: 49.

13. Morgan DJ et al., 2007. Brain magnetic resonance imaging white matter lesions are frequent in HTLV-I carriers and do not discriminate from HAM/TSP. AIDS Res Hum Retroviruses 23: 1499-1504.

14. Silva MTT, Mattos $P$, Alfano A, Araújo AQC, 2003. Neuropsychological assessment in HTLV-1 infection: a comparative study among TSP/HAM, asymptomatic carriers, and healthy controls. J Neurol Neurosurg Psychiatry 74: 1085-1089.

15. Gascón MRP, Casseb J, Smid J, Vidal JE, Fonseca LAM, Paiva A, Haziot MJ, Penalva de Oliveira AC, 2017. Cognitive impairment is frequent among symptomatic carriers of human T-cell lymphotropic virus type 1 (HTLV-1), regardless of their clinical status. J Neurol Sci 377: 185-189.

16. Raulino Goncalves L, Fernandes Barbosa LN, Machado Ribeiro Magalhaes P, Sampaio Rocha-Filho PA, 2017. Characterization of cognitive performance and evaluation of quality of life among patients with HTLV-1. Clin Neurol Neurosurg 160: 142-146. 
17. Labanca $L$ et al., 2018. Vestibular-evoked myogenic potential triggered by galvanic vestibular stimulation may reveal subclinical alterations in human T-cell lymphotropic virus type 1associated myelopathy. PLoS One 13: e0200536.

18. Nakagawa M, Izumo S, ljichi S, Kubota H, Arimura K, Kawabata M, Osame M, 1995. HTLV-I-associated myelopathy: analysis of 213 patients based on clinical features and laboratory findings. J Neurovirol 1: 50-61.

19. Gomes-Oliveira MH, Gorenstein C, Neto FL, Andrade LH, Wang YP, 2012. Validation of the Brazilian Portuguese version of the beck depression inventory-II in a community sample. Braz $J$ Psychiatry 34: 389-394.

20. Memõria CM, Yassuda MS, Nakano EY, Forlenza OV, 2013. Brief screening for mild cognitive impairment: validation of the Brazilian version of the Montreal cognitive assessment. Int J Geriatr Psychiatry 28: 34-40.

21. Gotuzzo E, Cabrera J, Deza L, Verdonck K, Vandamme A-M, Cairampoma R, Vizcarra D, Cabada M, Narvarte G, De las Casas C, 2004. Clinical characteristics of patients in Peru with human $T$ cell lymphotropic virus type 1-associated tropical spastic paraparesis. Clin Infect Dis 39: 939-944.

22. Castro-Costa CM, Araujo Ade Q, Camara CC, Ferreira AS, Santos Tde JT, de Castro-Costa SB, Alcantara RN, Taylor GP, 2009. Pain in tropical spastic paraparesis/HTLV-I associated myelopathy patients. Arq Neuropsiquiatr 67: 866-870.

23. Sato T et al., 2018. Proposal of classification criteria for HTLV-1associated myelopathy/tropical spastic paraparesis disease activity. Front Microbiol 9: 1651.

24. Anderson S, Jenkins K, 2015. Electrophysiologic assessment of auditory training benefits in older adults. Semin Hear 36: 250-262.

25. Coler-Reilly ALG, Yagishita N, Suzuki H, Sato T, Araya N, Inoue E, Takata A, Yamano Y, 2016. Nation-wide epidemiological study of Japanese patients with rare viral myelopathy using novel registration system (HAM-net). Orphanet $J$ Rare Dis 11: 69.

26. Fukushima T, Ikeda T, Uyama E, Uchino M, Okabe H, Ando M, 1994. Cognitive event-related potentials and brain magnetic resonance imaging in HTLV-1 associated myelopathy (HAM). J Neurol Sci 126: 30-39.

27. Zorzi G, Mancuso R, Nardocci N, Farina L, Guerini FR, Ferrante P, 2010. Childhood-onset HAM/TSP with progressive cognitive impairment. Neurol Sci 31: 209-212.

28. Canale A, Albera R, Lacilla M, Canosa A, Albera A, Sacco F, Chio A, Calvo A, 2017. Acoustic reflex patterns in amyotrophic lateral sclerosis. Eur Arch Otorhinolaryngol 274: 679-683.

29. Nasreddine ZS, Phillips NA, Bédirian V, Charbonneau S, Whitehead V, Collin I, Cummings JL, Chertkow H, 2005. The montreal cognitive assessment, MoCA: a brief screening tool for mild cognitive impairment. J Am Geriatr Soc 53: 695-699.

30. Gates GA, Anderson ML, McCurry SM, Feeney MP, Larson EB, 2011. Central auditory dysfunction as a harbinger of alzheimer dementia. Arch Otolaryngol Neck Surg 137: 390.

31. Polich J, 2007. Updating P300: an integrative theory of P3a and P3b. Clin Neurophysiol 118: 2128-2148.

32. Allain J-P, Stramer SL, Carneiro-Proietti ABF, Martins ML, Lopes da Silva SN, Ribeiro M, Proietti FA, Reesink HW, 2009. Transfusion-transmitted infectious diseases. Biologicals 37: 71-77.

33. Matos Cunha LC, Tavares MC, Criollo CJT, Labanca L, Dos Santos Couto Paz CC, Martins HR, De freitas carneiroProietti AB, Goncalves DU, 2013. Contribution of galvanic vestibular stimulation for the diagnosis of HTLV-1-associated myelopathy/tropical spastic paraparesis. J Clin Neurol 9: 252-288. 